\title{
Chão de terra batida
}

Jesser de Souza

P

articipei de uma oficina com Luís Otávio Burnier recém-chegado de seus anos de estudo na Europa. Não entendi absolutamente nada do que ele propunha; todos aqueles exercícios eram, de maneira geral, extremamente exaustivos e, enquanto abordagem, muito diferentes daquilo que eu conhecia como teatro, ou como exercícios de teatro. No entanto, por menos compreensível que aquilo se me apresentasse, essa oficina permaneceu em mim como uma vivência especial, intensa, instigadora.

Nosso encontro seguinte aconteceu em 1990, quando ingressei no curso de Artes Cênicas da Unicamp. De 1990 a 1992 tive aulas de Expressão Corporal e Mímica de Etienne Decroux com Luís Otávio Burnier. Nutria uma admiração especial pelo rigor e seriedade do professor, assim como pela entusiástica paixão com que falava da obra de seu mestre Decroux e dos anos de convívio com ele, como seu assistente.

No final de 1992, penúltimo ano de curso, minha turma convidou Burnier para dirigir nossa montagem de formatura, no ano seguinte. Em resposta a nosso convite ele comentou, aludindo aos encontros ocasionais nos finais de semana em que íamos ensaiar no DAC (e ele treinar com Simioni e Ricardo): "Não sei se vocês são bons atores, mas vejo que são como formigas: vocês trabalham!". Foram seis meses ininterruptos de trabalho de assimilação das técnicas e dos exercícios que vinham sendo desenvolvidos pelos atores do Lume de então: treinamentos físico, energético e vocal, além de mímesis corpórea e condicionamento físico (força e alongamento). Para o Lume, esse trabalho, soube mais tarde, serviu como constatação de que aquele treinamento, praticado há oito anos, era transmissível e eficaz para os alunos também a médio prazo.

Após esse período de treinamento e criação de matrizes, ${ }^{1}$ a direção para a qual apontava o tema da futura montagem eram as lendas e os mitos brasileiros. Burnier nos propôs, então, realizar viagens de pesquisa de campo. "Vocês querem falar sobre os mitos e as lendas de um povo. Vocês conhecem este povo?”, perguntounos Burnier. Cada ator partiu para uma região do país para conhecer, conviver e aprender com esse povo, coletando ações físicas e vocais, "causos" e cançôes. Mais que "coletar materiais"

Jesser de Souza é ator do Lume.

1 Sobre "matriz", indico o capítulo homônimo na dissertação de mestrado de Raquel Scotti Hirson: "Tal Qual Apanhei do Pé". 
para a futura montagem, minha viagem de pesquisa para a Amazônia serviu para abrir espaços, sensibilizar o olhar para o outro, permitirme ser afetado pelas pessoas que conheci e pela realidade que as envolvia. $\mathrm{O}$ modo simples e pleno de viver daquela gente - índios, caboclos e populaçóes ribeirinhas - exercia em mim um profundo fascínio e fazia vibrar algo que eu sabia estar relacionado às minhas origens.

De volta a Campinas, demos início à montagem que teve como título "Taucoauaa Panhé Mondo Pé”, que em língua geral indígena significa: "Histórias que o povo conta". O espetáculo falava dos mitos brasileiros, fazendo uso das matrizes surgidas do treinamento técnico e da mímesis corpórea das pessoas observadas durante a viagem.

A experiência do treinamento, as inquietaçôes que provocou e o aprimoramento técnico que promoveu impulsionaram alguns dos colegas de montagem e a mim a propor um estágio no Lume, para darmos continuidade às nossas descobertas. $\mathrm{O}$ ano seguinte à formatura foi de treinamento, orientado por Burnier e assessorado por Simioni, em que pudemos mergulhar um pouco mais na investigação individual, trabalhando muitas vezes sozinhos. A contrapartida dessa assessoria era a contribuição que cada um pudesse dar à precária estrutura administrativa do Lume, que não contava com funcionários em número suficiente para tudo que desejava realizar. Assim, nós estagiários colaborávamos na redação de projetos, na função de secretariado, na organização dos arquivos de documentos, jornais e fotos, primeiros passos na implementação de computação, assessoria de imprensa, produção, operação de luz e de som para os espetáculos do Lume, Valef Ormoso e Kelbilim, o Cão da Divindade, o primeiro dos espetáculos do grupo.
Com a inserção dos estagiários na estrutura do Lume, justificava-se a petição, junto à Unicamp, de uma sede para o então Laboratório de Movimento e Expressão do Instituto de Artes da Unicamp, que logo depois se tornou o Núcleo Interdisciplinar de Pesquisas Teatrais Lume, ligado à reitoria. No final de 1994, a Universidade aluga a atual sede do Lume, na Vila Santa Izabel, no distrito de Barão Geraldo, em Campinas. Assim, pela primeira vez em nove anos, o Lume teria um espaço para treinamento de atores que não fosse emprestado de alguém. Por muitos anos, os treinamentos e os ensaios eram realizados no salão de festas da $\mathrm{Pa}$ róquia de Santa Izabel ou em salas emprestadas pelos departamentos de Artes Cênicas e de Educação Física.

A aquisição da sede coincidiu com o final de uma fase do Lume, prevista por Burnier para os dez primeiros anos, dedicada quase exclusivamente ao mergulho em sala de trabalho, que precederia a fase seguinte, de experimentação dos resultados das pesquisas na criação de espetáculos, associada à divulgação e "publicação" das mesmas por meio da apresentação dos espetáculos. Graças a ela, estava aberta a possibilidade de estender o trabalho ao público, criar e difundir a criação, promover cursos e intercâmbios. Como na época não tínhamos uma estrutura adequada para fixação de refletores, nem equipamentos de iluminação e sonorização, fazíamos apresentações ao ar livre durante a tarde nos finais de semana. O público era acomodado sob a sombra do enorme flamboyant em frente à Sala Verde,,$^{2}$ em arquibancadas construídas para a montagem do espetáculo de formatura. O primeiro espetáculo a ser apresentado foi Valef Ormoso. ${ }^{3}$ A entrada era franca e convidávamos amigos, vizinhos e estudantes para o evento que chamamos de "Lume Apresenta".

2 Nome dado à nossa sala de treinamento em alusão à cor do chão original, hoje coberto por piso de madeira.

3 Espetáculo de clown criado em 1992 e representado por Luís Otávio Burnier, Carlos Simioni e Ricardo Puccetti. 
Ao final deste ano de estágio, desejosos de prosseguir com as pesquisas e o trabalho que vínhamos empreendendo, propusemos sua continuação. Desta vez, no entanto, Burnier selecionou os atores com os quais gostaria de dar continuidade às pesquisas. Ele me escreve em 22 de dezembro de 1994:

Durante o ano de 1995 pretendo, no que tange às minhas pesquisas, dar continuidade nas buscas individuais iniciadas com os atorespesquisadores do Lume desde 1985, e na busca iniciada com alguns atores-estagiários em 1993. Não pretendo, portanto, aceitar novos estagiários, mas me aprofundar no estudo da Arte de Ator que alguns dentre os atores que vêm trabalhando comigo, por motivos diversos, me permitem experimentar.

Assim, a equipe com a qual pretendo me aprofundar em questôes ligadas ao que hoje chamo de 'Dança Pessoal' é composta pelos seguintes atores: Carlos Simioni, Ricardo Puccetti, Luciene, Renato, Raquel e Ana Cristina.

A equipe com a qual pretendo me aprofundar principalmente em questôes ligadas ao que chamo de 'Mímesis Corpórea' - área de concentração proposta: o estudo do caboclo e o interiorano do Estado de São Paulo - é composta por: Ana Elvira e Jesser.

Ainda não tenho claro como devo conduzir e operacionalizar os trabalhos comuns e os específicos de cada equipe. [...] Os trabalhos comigo deverão ter início em Fevereiro de 1995.

Em fevereiro de 1995, nos encontramos na sede do Lume para o primeiro dia de trabalho prático daquela nova fase do estágio e, coincidentemente, para a inauguração do novo piso de madeira da Sala Verde. Ao final do trabalho, Burnier nos reuniu em círculo e, no centro da roda, expressando-se através de mímica, passou diante de cada um dos atores que havia definido como sua equipe, plantando simbolicamente uma semente em cada um dos coraçóes. Em seguida, plantou sua última semente no chão da Sala Verde.

Esta é minha última lembrança de Luís Otávio Burnier em vida.

No dia seguinte não pode vir treinar conosco, pois estava enfermo.

Poucos dias depois faleceu.

Seguramente, esse foi o período mais difícil da história do Lume. Sem Luís Otávio Burnier parecia quase impossível seguirmos adiante. Ele era a figura central do grupo, o mentor intelectual, o idealizador do Lume, aquele que vinha realizando um trabalho capaz de dar autonomia ao ator. Mas, nesse momento, imperou em cada um dos atores da equipe o desejo de continuidade e a crença quase cega na exeqüibilidade do ideal de Burnier. O período que se seguiu, apesar da lacuna deixada por Burnier, foi de extrema fertilidade criativa. Fez-se necessário, para superar sua ausência, construir uma identidade de grupo e retificar a relevância do Lume enquanto projeto de pesquisa em teatro, em particular da Arte de Ator, dentro e fora da academia, ainda que sem a figura de seu idealizador. Percebemos que seria possível fazer de nossa sede um centro de difusão cultural e artística, com enfoque no trabalho do ator e no teatro de grupo e de pesquisa. Começava no Lume a fase pós-Burnier.

O primeiro evento dessa fase, ocorrido em 1995, foi a "Mostra de Maio", em que foram apresentados os espetáculos Cnossos, Cravo, Lírio e Rosa, Mixórdia em Marcha-Ré Menor, Anoné e Contadores de Estórias, a grande maioria inéditos. Com o apoio da FAPESP, o Lume adquiriu equipamento de iluminação, o que tornou possível a apresentação de espetáculos em nossa pequena Sala Verde, ainda hoje com seus $9 \times 8 \mathrm{~m}$ e capacidade para sessenta espectadores. Cnossos era um espetáculo de e com Ricardo Puccetti, resultante das pesquisas sobre dança pessoal, que já vinha sendo dirigido por Burnier. A direção foi concluída com o olhar externo de Ana Cristina Colla e Renato Ferracini. Cravo, Lírio e Rosa, espetáculo de clown com Ricardo Puccetti e Carlos Simioni, foi uma 
adaptação e recriação do espetáculo Valef Ormoso, no qual ambos atuavam com Burnier. Mixórdia em Marcha-Ré Menor foi um trabalho dirigido por Ricardo Puccetti com alunos/atores, que faziam parte da oficina de clown que ministrava. Anoné, espetáculo dirigido por Carlos Simioni, com todos os atores do Lume de então, foi a experimentação prática de aplicação dos resultados do intercâmbio realizado com a bailarina japonesa de butoh Natsu Nakajima, em abril de 1995. Contadores de Estórias foi o espetáculo itinerante criado pelos ex-estagiários, ${ }^{4}$ que se tornaram membros do corpo de atores-pesquisadores do Lume em 1995, dirigidos por Ricardo Puccetti. O espetáculo resultava das pesquisas de mímesis corpórea, aproveitando muito do material coletado na pesquisa de campo para a montagem do espetáculo de formatura.

Em 1996 passa a assumir a coordenação do Lume Suzi Frankl Sperber, professora de Teoria Literária do Instituto de Estudos da Linguagem da Unicamp. A contribuição da professora Suzi foi e tem sido imprescindível para o grupo, não apenas no que diz respeito à teorização sobre a arte de ator, mas também por seu empenho, estímulo e orientação de muitos projetos. Por sua iniciativa foi criada a Revista do Lume, veículo para discussão e reflexão sobre a arte de ator, hoje em sua sexta edição.

Também em 1996 o Lume passa a oferecer workshops e assessorias de treinamento para atores. Em 1997 realiza um intercâmbio sobre mímesis corpórea com a atriz, bailarina e coreógrafa Anzu Furukawa, que objetivava o confronto de metodologias e resultou na montagem do espetáculo Afastem-se vacas, que a vida é curta, inspirado na obra Cem Anos de Solidão, de Gabriel Garcia Marques, um dos trabalhos de vida mais curta e, para mim, um dos mergulhos mais profundos no universo do butoh e da dança pessoal. Para esse intercâmbio, desenvolvemos pesquisas de campo na região amazôni$\mathrm{ca}$, junto a populaçôes indígenas e ribeirinhas.

Desde então, temos realizado e promovido intercâmbios com grupos de teatro do Brasil, gerando uma rede de "grupos irmãos" e relações aprofundadas com artistas internacionais como Natsu Nakajima (Japão), Anzu Furukawa (Japão), Nani Colombaioni (Itália) e Kai Bredholt (Dinamarca). Atualmente mantemos contato estreito e temos realizado projetos em parceria com Sue Morrison (Canadá), Tadashi Endo (Japão/Alemanha), Norberto Presta (Argentina/Itália) e Leris Colombaioni (Itália). Alguns desses mestres atuaram ou vêm atuando como diretores e/ou colaboradores na criação de novos espetáculos do Lume.

Tenho tido a oportunidade de estar próximo e aprender com esses mestres do teatro e da dança butoh, todos estrangeiros. Mas, mesmo com eles, acabo sempre buscando paralelos entre meu trabalho de ator e as manifestações populares brasileiras. Há dois anos, tenho a oportunidade e o privilégio de manter contato com os mestres Duda Bilau, Inácio Lucindo, Bíu Alexandre, Bíu Roque e Aguinaldo Silva, todos simples e grandes mestres, todos generosos mestres de uma "brincadeira" popular de Pernambuco, o "Cavalo Marinho". Tenho tido contato também com Paulinho Sete Flechas, mestre de uma dança também pernambucana, o "Caboclinho". Quando estou perto deles, sinto latente minha raiz, meu chão de terra batida, meu terreno fértil. São todos mestres/atores/ dançarinos, cuja magnitude poderia, sem exageros, ser comparada à de um Kazuo Ohno, pois detêm um conhecimento que está neles, é eles e é o que eles fazem.

Desde o contato com esses mestres, tenho me dedicado a buscar paralelos entre essas danças e a pesquisa de ator. Ainda não considero

4 Ana Cristina Colla, Ana Elvira Wuo, Jesser de Souza, Luciene Domeniconi Crespilho, Raquel Scotti Hirson e Renato Ferracini. 
que saiba dançá-las bem, ou bem como gostaria, mas a apropriação e a transformação delas para o trabalho do ator-dançarino já vem sendo empreendida por dois grupos para os quais presto assessoria. São eles o Grupo MunduRodá, de São Bernardo do Campo, composto por Juliana Pardo e Alício Amaral e o Grupo Peleja, de Barão Geraldo, formado por alunos de várias áreas da Unicamp e coordenado por Daniel Campos. Vários exercícios vêm sendo criados por esses grupos, com o objetivo de elaborar e sistematizar um treinamento para o ator extraído das danças populares brasileiras.

Alguns dos artistas são também músicos e agregam à pesquisa corporal a musicalidade dessas manifestações. Ambos os grupos estão em fase de construção de espetáculos, com conclusão prevista para o próximo ano, sendo um deles - o do grupo MunduRodá - sob minha direção.

\section{Referências bibliográficas}

BURNIER, Luís Otávio. A arte de ator: da técnica à representação. Elaboração, codificação e sistematização de técnicas corporais e vocais de representação para o ator. Campinas: Unicamp, 2001.

REVISTA DO LUME. Campinas: Unicamp, v. 1, 1998.

HIRSON, Raquel Scotti. Tal Qual Apanhei do Pé. Campinas: Dissertação de Mestrado - IA-Unicamp, 2003. 